\title{
Zoques Chimalapas. Reconfiguraciones IDENTITARIAS PARA LA DEFENSA DEL TERRITORIO
}

\author{
Chimalapas' Zoque People. Identity \\ RECONFIgURATIONS FOR TERRITORIAL DEFENSE
}

\section{Iliana Amoroz Solaegui ${ }^{1}$}

Resumen: La vida comunitaria de los pueblos indígenas en México y América Latina está asediada y amenazada por el mayor embate contemporáneo de las políticas neoliberales, que la fragmenta y la saquea mediante el despojo de sus territorios, de sus tierras, de sus bienes comunes y la expulsión de su gente. Este artículo resume la histórica lucha y resistencia del pueblo zoque chimalapa, que se organiza para defender su territorio, la comunidad y la vida. En Los Chimalapas, las luchas ancestrales y las actuales se entretejen y reconfiguran al interior del territorio desde la identidad, posicionándose hacia el exterior a contracorriente de un desarrollo que se impone sin su participación. Ésta es una lucha por el territorio que involucra la identidad y la cultura. El territorio como un referente para una construcción identitaria enmarcada por relaciones de poder y por la defensa estratégica de sus derechos como pueblo zoque chimalapa.

Palabras clave: chimas, zoques, historia, Oaxaca, Chiapas.

\footnotetext{
${ }^{1}$ Etnóloga por la Escuela Nacional de Antropología e Historia, ENAH. Maestra en Desarrollo Rural por la Universidad Autónoma Metropolitana, UAM-X. Autora del libro Los Chimalapas. Conflictos, identidades y la defensa del territorio, 2014, Seculta, Oaxaca. Temas de investigación: movimientos indígenas, identidad, cultura, territorio, Derechos Humanos, Derechos de los Pueblos Indígenas, salud rural, salud colectiva, género, educación popular. Correo electrónico: iliana.amoroz@gmail.com Fecha de recepción: 0710 14; Fecha de aceptación: 130415.
} 


\section{Iliana AmorozSolaegui Zoques Chimalapas. Reconfiguraciones...}

Abstract: Community life of indigenous peoples in Mexico and Latin America is besieged and threatened by current neoliberal policies. These policies fragment and loot indigenous communities through the plunder of their territories, land, commons and the expulsion of their inhabitants. This article summarizes the historical struggle and resistance of the people of Los Chimalapas, who have organized themselves to defend their territory, community and life. In Los Chimalapas, ancestral and current struggles are interwoven and reconfigured within the territory based on their identity, and positioned outwards against a development unrelated to their needs. This is a fight for territory involving identity and culture. Territory as a reference for an identity construction framed by power relations and by the strategic defense of their rights as Zoque-Chimalapa people.

Keywords: chimas, zoques, history, Oaxaca, Chiapas.

\section{Introducción}

La región de los Chimalapas la conforman dos municipios: Santa María y San Miguel Chimalapas, con una extensión de 594,000 hectáreas. Se localiza en la región del Istmo de Tehuantepec. Es un territorio conocido por su gran riqueza en recursos naturales, distribuidos en aproximadamente 300,000 mil hectáreas de bosques y selvas donde se encuentra una amplia diversidad de especies de fauna y flora, muchas de las cuales son endémicas; presenta corrientes de agua muy importantes, como las del río Coatzacoalcos y Uxpanapa, parte del sistema Grijalva-Usumacinta y los ríos Chicapa y Ostuta, que desembocan en el Sistema Lagunar Huave. Chimalapas es considerada una de las regiones de mayor biodiversidad del continente americano $y$, por ende, del mundo.

Como la gran mayoría de los territorios de los pueblos indígenas, el territorio y las comunidades chimalapas han sufrido grandes transformaciones, especialmente a partir del siglo XX, ocasionadas por políticas públicas de corte neoliberal que amenazan, fragmentan y 


\section{Iliana AmorozSolaegui Zoques Chimalapas. Reconfiguraciones...}

dividen su vida comunitaria mediante el despojo de sus territorios, de sus tierras, de sus bienes comunes y la expulsión de su gente.

El pueblo originario habitante y dueño históricamente de este territorio es el zoque, que se rige bajo la propiedad de tenencia de la tierra comunal, siendo de las pocas propiedades comunales extensas que quedan aún en el país. Los zoques de las comunidades chimalapas han desentrañado las viejas y nuevas amenazas que enfrentan con las políticas desintegradoras, debido principalmente a una localización estratégica para México y el Continente: el Istmo de Tehuantepec. Región estratégica para la economía y la comunicación continental, donde grandes políticas de desarrollo han atravesado la zona, desde la construcción del ferrocarril a finales del siglo XIX, las políticas de colonización del trópico húmedo entre las décadas de 1940 a 1960, el Plan Puebla Panamá (PPP), a partir de 2001, y su continuidad actual con el Plan Mesoamericano. A lo que se han sumado proyectos de explotación minera que actualmente están considerados en la región.

Al mismo tiempo, las políticas conservacionistas a ultranza, de corte neoliberal, han tenido sus efectos en la región Chimalapas, con la propuesta de declarar Reserva de la Biosfera un área de 400,000 mil hectáreas en buen estado de conservación que se encuentran en el corazón del territorio de los Chimalapas, a lo cual sus pobladores se han negado rotundamente.

En la última década esta región ha sido caracterizada como de alta conflictividad por parte del gobierno federal y estatal debido a una serie de conflictos agrarios y ambientales. En 2003 la región fue considerada uno de los catorce "focos rojos" de todo el país que identificaba la Secretaría de la Reforma Agraria (SRA) debido a sus conflictos, principalmente los derivados de las invasiones de ganaderos, talamontes, ejidatarios chiapanecos y narcotraficantes; y por otro lado, a la sobreposición de planos y la falta de deslinde de las tierras que, de acuerdo con las resoluciones presidenciales que poseen los habitantes de la zona desde 1967, les pertenecen a los zoques.

La ubicación fronteriza de las comunidades de la zona oriente ha ocasionado que, desde su fundación en la década de 1970, estén en permanente conflicto, principalmente con los ejidos chiapanecos que 


\section{Iliana AmorozSolaegui Zoques Chimalapas. Reconfiguraciones...}

se han instalado legal e ilegalmente — por sobreposición de títulos agrarios - en bienes comunales de los municipios chimalapas. Estas invasiones a los bienes comunales del territorio Chimalapas han sido presentadas políticamente, en su mayoría de veces, como un problema de límites entre Oaxaca y Chiapas.

Mapa 1.

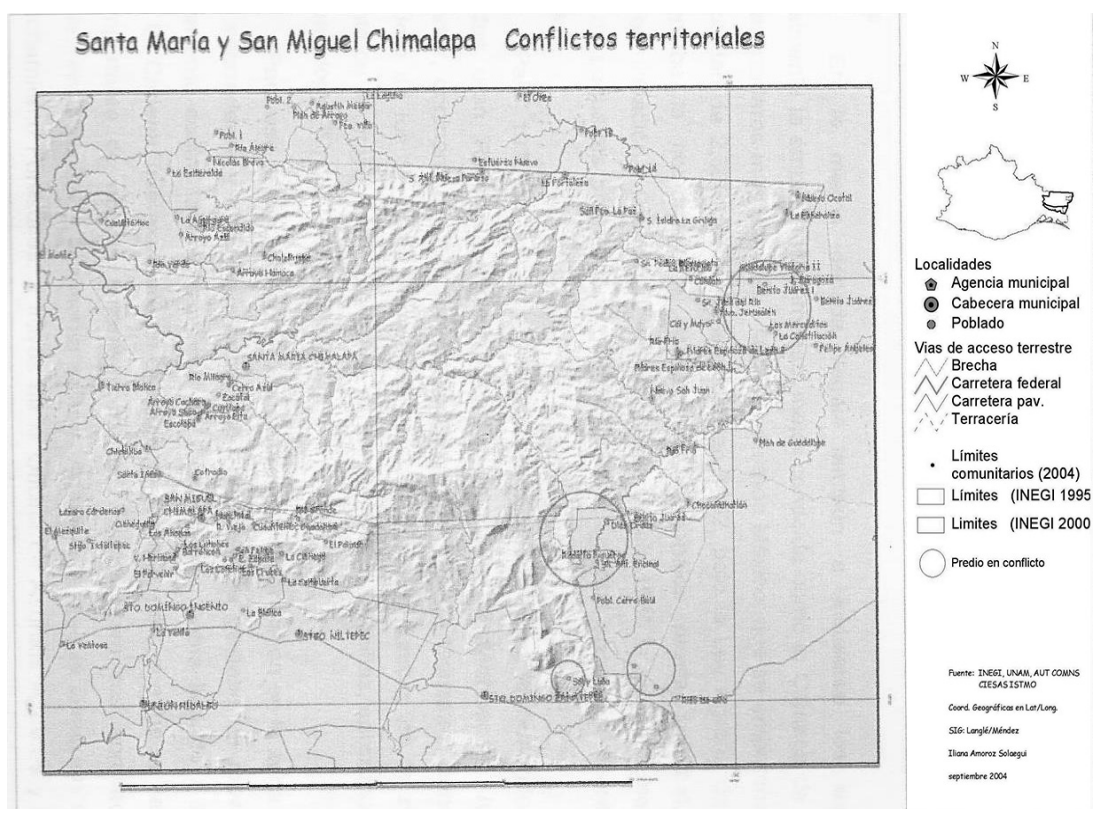

En las últimas décadas las comunidades también han sido pobladas por personas tsotsiles y tseltales, como parte de la migración forzada debido a los conflictos religiosos y agrarios en la región Altos de Chiapas desde la década de 1970; llegan también zoques de Chiapas a partir de 1986, cuando hace erupción el volcán El Chichonal; y mestizos originarios de Michoacán, Guerrero, Puebla, Veracruz y la ciudad de Oaxaca, entre las décadas de 1950 y 1970, cuando se inicia la explotación forestal en la región, para emplearse como obreros en los aserraderos que funcionaban justo en la frontera entre Oaxaca y Chiapas. La conformación de una población indígena y mestiza diversa 


\section{Iliana AmorozSolaegui Zoques Chimalapas. Reconfiguraciones...}

y su ubicación geográfica de frontera de la zona oriente ha devenido en una zona social, cultural y política heterogénea.

El problema agrario en la zona oriente enmarca y da paso a actividades clandestinas como el narcotráfico, la tala de árboles y el saqueo de especies animales y vegetales, además de las recurrentes invasiones por parte de ejidatarios. Esto a su vez ha generado una serie de consecuencias para las comunidades: una población, paradójicamente, pobre, desgastada y en desventaja para el aprovechamiento de los recursos, marcada por los conflictos e invirtiendo gran parte de su tiempo en la defensa del territorio, mismo que se encuentra en un claro deterioro.

En este proceso de colonización, de invasiones y políticas neoliberales, se fue gestando desde la década de 1970 un proceso organizativo de defensa del territorio en la zona oriente del municipio San Miguel Chimalapa, siendo una de sus estrategias la fundación de nuevas comunidades por parte de sus pobladores. A partir de este momento, las comunidades han rechazado y detenido proyectos de desarrollo, han fundado pueblos en las zonas invadidas, han realizado acciones directas contra el saqueo de especies, de madera y contra el narcotráfico. Han hecho alianzas con personas provenientes de otras regiones, organizaciones y comunidades para mejorar su calidad de vida atendiendo sobre todo la defensa del territorio.

En los Chimalapas, la cultura es cambiante, dinámica, sus habitantes retoman lo que les sirve de su identidad como zoques y lo resaltan y actualizan en el plano organizativo y político, poniendo énfasis en el criterio de autoadscripción, pero también en el de diferenciación e identificación para la construcción de nuevas identidades, como la identidad chima, que de ninguna manera excluye a otras - la étnica, religiosa, de clase, de género-, y les ha permitido un posicionamiento frente a una concepción mercantil de la tierra y del territorio, que implica relaciones de dominación.

En este sentido el territorio ha sido un referente identitario ya no solamente de los zoques, sino también de los migrantes actualmente asentados en la región, esto ha llevado a una identificación de pertenencia al territorio más allá del aspecto étnico. La defensa del territorio involucra a zoques, tsotsiles y mestizos, lo cual ha devenido en 


\section{Iliana AmorozSolaegui Zoques Chimalapas. Reconfiguraciones...}

una identidad colectiva, una identidad chima, cuya raíz está sustentada en la memoria histórica de los habitantes zoques, pero que incluye una población diversa, heterogénea, que acepta los bienes comunales del territorio chimalapa.

Es decir, una construcción de la territorialidad por parte de los chimas íntimamente relacionada con la vida cotidiana, la organización comunitaria, con el ser comunero, la identificación, la solidaridad, la reconstrucción de la historia, los recursos naturales y la defensa del territorio, presentándose así, en el escenario político de la confrontación y la negociación, como "pueblo chimalapa", apelando a sus derechos colectivos en tanto pueblos indígenas. ${ }^{2}$

En este trabajo queremos esbozar algunos de los resultados y planteamientos de una investigación ${ }^{3}$ realizada en tres comunidades de la zona oriente del municipio de San Miguel Chimalapa. Dicha investigación tuvo por objetivo central comprender los procesos de construcción de nuevas identidades, enmarcados por los conflictos territoriales y agrarios. Los objetivos siguientes tendieron al conocimiento de la vida cotidiana de sus pobladores; la apropiación y construcción social, cultural y simbólica del territorio; además de los procesos históricos de organización de este pueblo para la defensa de su territorio.

Para sustentar el estudio de la construcción de la identidad chima, se utilizó la propuesta metodológica de relaciones triádicas, ${ }^{4}$ con la que se analizaron las construcciones identitarias a partir de la identificación de los actores sociales involucrados desde diferentes posiciones, tanto del interior como del exterior de las comunidades

\footnotetext{
${ }^{2}$ Hacemos referencia a la categoría de "pueblo" en vez de "etnia" por la connotación política que ésta adquiere a partir de la entrada en vigor del Convenio 169 sobre Pueblos Indígenas y Tribales en Países Independientes de la Organización Internacional del Trabajo (OIT). Y desde la connotación identitaria, organizativa y política que los chimas le dan.

3 Tesis de licenciatura en Etnología, ENAH, con el título Chimalapas. Cultura, resistencia y derechos indígenas (2008). Posteriormente publicada como Los Chimalapas. Conflictos, identidades y la defensa del territorio, 2014, Seculta-Gobierno de Oaxaca.

${ }^{4}$ Una propuesta que retomamos de la doctora Marcela Coronado Malagón en Procesos de etnicidad de los zapotecos del Istmo de Tehuantepec: una relación tríadica entre la resistencia y la dominación, 2004, tesis de doctorado en antropología, ENAH.
} 


\section{Iliana AmorozSolaegui Zoques Chimalapas. Reconfiguraciones...}

que se encuentran en la frontera de los conflictos, desde cuyas posiciones tienen su propia versión de éstos y de su historia.

El primer actor social que identificamos es el nosotros, con una adscripción social y originaria a una comunidad zoque. El segundo actor lo constituyen los otros, las personas que no son zoques pero que viven en el territorio, con quienes los zoques desarrollan relaciones interétnicas cotidianas: tsotsiles, mestizos y zoques de Chiapas; así conforman a los chimas, y se reconocerá como un actor social al que llamaremos los otros/nosotros. En las relaciones entre estos dos primeros actores incide un tercero antagonista: el "otro dominante", constituido por los agentes externos que dominan y subordinan la región, sus recursos y su gente. Los chimas identifican a éstos como agresores hacia el territorio: ejidos, instituciones de gobierno, talamontes, narcotraficantes, proyectos de desarrollo, y similares.

Las relaciones entre el actor nosotros y el otros/nosotros son en ocasiones conflictivas y contradictorias, pero en la interacción con el otro dominante se constituyen en nosotros/nosotros: los chimas, producto de esta tríada conforman un proceso de identidad colectiva con un referente territorial, que incluye procesos de etnicidad y la constitución política de los chimas, relación estratégica para la defensa del territorio.

Figura 1. Relaciones triádicas en la zona oriente de San Miguel Chimalapas

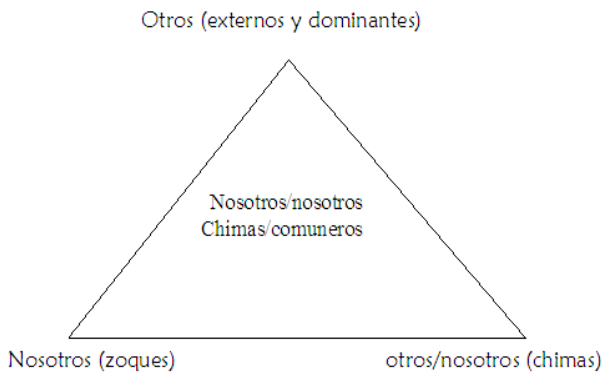

Fuente: Elaboración propia. 


\section{Iliana AmorozSolaegui Zoques Chimalapas. Reconfiguraciones...}

Bonnemaison (1981) plantea que pueden distinguirse dos funciones principales del territorio: una de orden político — la seguridad-; otra de orden más específicamente cultural —la identidad—. Según las épocas históricas y los modelos de civilización, los problemas de identidad o de seguridad se plantean en términos diferentes, y desde entonces el diseño del territorio, su coherencia, sus contornos, sus sistemas de polarización se modifican.

\section{Nosotros: los zoques}

En este apartado presentamos al primer actor de la tríada: nosotros. Recapitulando la historia de los procesos de poblamiento del territorio y su apropiación por parte de los zoques a través de un periodo de larga duración, el cual se remonta a los zoques como grupo etnolingüístico.

El poblamiento del territorio Chimalapa es resultado de un proceso histórico en el que los zoques se asumen como dueños ancestrales — simbólica y materialmente- de estas tierras. Desde tal perspectiva, como grupo étnico provienen y comparten una historia particular propia (Bonfil, 1994). La historia de los zoques en tanto grupo etnolingüístico se remonta aproximadamente a 3,000 años de presencia en el Istmo de Tehuantepec, en lo que ahora son los estados de Chiapas, Oaxaca, Veracruz y Tabasco. Son considerados como descendientes culturales de los olmecas (Báez-Jorge, 1973) y pertenecientes a una matriz cultural todavía más antigua identificada como "mocaya", término que deriva del mixe-zoque y que significa "Gente de maíz". Esta tesis considera que los zoques llegaron desde Guatemala, donde se ubicaban hace 3,800, siendo la primera cultura que cultiva el maíz (Clark y Blake, 1993).

Su ubicación, en la época prehispánica, aparece delimitada de sus vecinos los mayas y posteriormente de los zapotecos; Gareth Lowe identifica a los zoques “[...] en un gran territorio que abarca desde el río Grijalva, abajo del Cañón de la Angostura hasta el Océano Pacífico y desde allí cruzando el Istmo al oeste y norte hasta el Golfo de México" (Lowe, 1983: 127). 


\section{Iliana AmorozSolaegui Zoques Chimalapas. Reconfiguraciones...}

El mismo autor reconoce grupos culturalmente diferenciados de esta gran familia proto-mixe-zoque: los mixes-zoques, mixes popolucas, y zoques popolucas, además de los tapachultecos (Lowe, 1983). Estudios lingüísticos posteriores han confirmado esta teoría y recientemente se ha hecho la clasificación del tronco lingüístico proto-mixe-zoque (Wichmann, 1995). Hallazgo que refuta la hipótesis de que los zoques pertenecen al tronco lingüístico macro-maya, como durante mucho tiempo se había afirmado (Figura 2).

Figura 2. Familia lingüística mixe-zoqueana

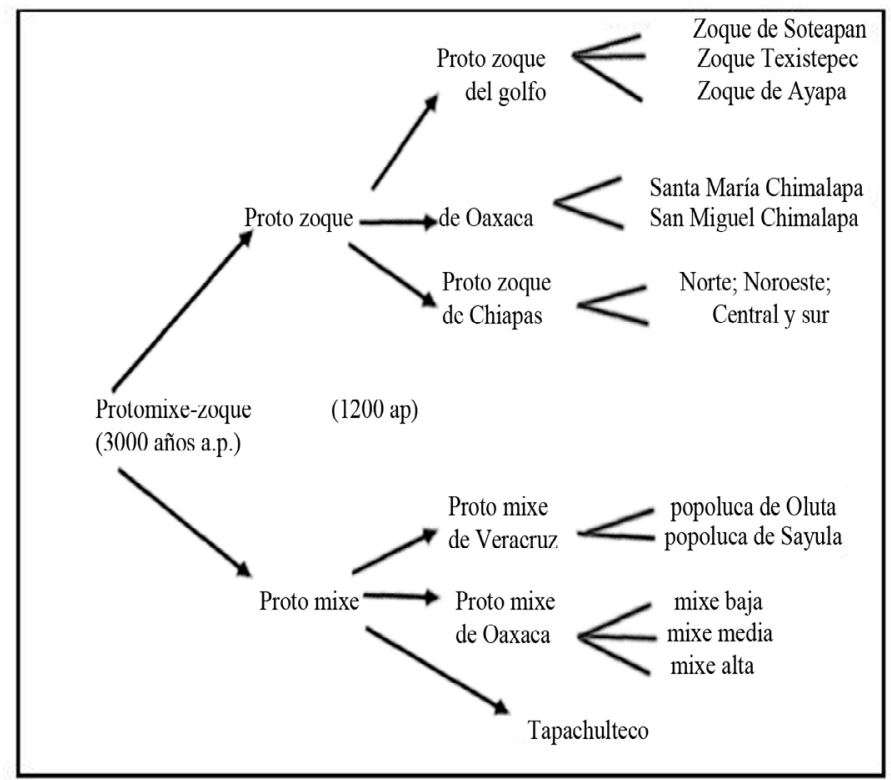

Fuente: Elaboración propia.

Durante la conquista, los mixes-zoques y los grupos mayenses “[...] compartieron una frontera que corría desde el norte, en la planicie costera del Golfo, aproximadamente a la altura de Comalcalco, Tabasco, y hacia el sur, entrando en Chiapas en línea recta hasta Tapachula sobre la Costa del Pacífico" (Lee, 1983: 90). 


\section{Iliana AmorozSolaegui Zoques Chimalapas. Reconfiguraciones...}

El periodo colonial implicó cambios y recomposiciones en este territorio, los zoques se vieron afectados debido a la organización que les imponían con las Leyes de Indias, les obligaban a vivir en comunidades, dejando tierras libres que ocuparon los españoles para la ganadería y el cultivo de la cańa de azúcar, asimismo padecieron la encomienda que duró hasta el siglo XVIII (Velasco, 1975). Consecuencia de lo anterior es que se produjo una importante reducción demográfica y territorial del área zoque.

La conformación del Estado nación implicó la fragmentación de territorios culturales. Hasta el día de hoy los zoques limitan con los nahuas y choles de Tabasco al noroeste, con los tsotsiles al este, al suroeste con los ikoots y zapotecos y al oeste con los mixes, repartidos en los estados de Chiapas, Oaxaca, Veracruz y Tabasco, siendo este último donde se localizan en menor cantidad, y en Chiapas donde se concentró la mayor cantidad de la población zoque. Los zoques de los Chimalapas son considerados como una microetnia separada del grupo etnolingüístico zoque (Barabas y Bartolomé, 1996).

El proceso de conformación territorial de los zoques chimalapas está ubicado a partir del año 1687, cuando Domingo Pintado compró 360 leguas cuadradas a la corona española, obteniendo así los títulos primordiales por la cantidad de 25 mil pesos oro, esto les hacía dueños de 900,000 hectáreas aproximadamente (García, 1999; De Teresa y Hernández, 2000). ${ }^{5}$ De aquí el nombre de Chimalapas, que en lengua zoque significa: chima-jícara, lapa-oro, para decir, "Jícara de oro". ${ }^{6}$ Algunos comuneros cuentan así este acontecimiento:

\footnotetext{
${ }^{5}$ Existen diversas versiones provenientes de funcionarios, académicos y activistas, que ponen en duda este hecho histórico, especialmente en cuanto a las jícaras llenas de oro se refiere. Sin embargo, pudimos encontrar algunas fuentes que nos permitieron considerar dicha posibilidad (Hoffmann, 2001). Para esta investigación tomamos en cuenta la versión que los chimas retoman y argumentan, en la que sustentan la defensa del territorio. Asimismo, los zoques tienen dos Resoluciones Presidenciales de 1967 que avalan las 594,000 hectáreas; resoluciones que les ha dado un valor legal y legítimo de saberse dueños de este territorio desde "tiempos inmemoriales" como zoques.

${ }^{6}$ Otro significado de Chimalapa en náhuatl es el de chimalli, escudo; $a$, agua y lapa, entre; "Entre escudos de agua". En este trabajo se reconoce la toponimia a partir de la referencia identitaria de la gente por su significado en zoque.
} 


\section{Iliana AmorozSolaegui Zoques Chimalapas. Reconfiguraciones...}

Los chimalapas son los dueños verdaderos, dueños de las tierras. Cuando la corona española en México fueron los gobernantes en el país, entonces los chimalapas compran esas tierras directamente a la corona española con una jícara de oro para que les devolverían sus propias tierras, porque los españoles estaban invadiendo las tierras de los chimalapas, entonces a través de algunos religiosos se organizan los chimalapas y van a la ciudad de México a entregarle una jícara de oro para que les entregaran sus montañas, sus tierras, y se quedó Santa María Chimalapa (entrevista. Benito Juárez, 15/04/02).

Santa María es el primer municipio que se fundó, anteriormente llamado Chimalapilla, un lugar que fue abandonado en 1737 consecuencia de una epidemia de viruela, trasladándose a lo que actualmente es la cabecera municipal, a 15 kilómetros al oeste del antiguo centro de población. El municipio de San Miguel se funda en 1780 por zoques provenientes de Copainalá, Chiapas:

Se entiende que los chimalapas se fueron refugiando, los expulsan de sus tierras y se fueron a meter allá por Copainalá, se fueron refugiando los señores más grandes de los Chimalapas, entonces por eso, cuando los chimalapas se reubican históricamente vienen de Copainalá, estado de Chiapas, se regresan a sus propias tierras. Por eso los chimalapas, como decía, estaban todos regados, pero cuando compran sus tierras regresan nuevamente a su territorio porque, así se entiende, son procedentes de Chiapas, por eso se dice que el patrón Miguelito que tienen en San Miguel es chiapaneco. Así se entiende históricamente, pero que son los mismos verdaderos que regresan a sus propias tierras (entrevista. Benito Juárez, 15/04/02).

La explotación de los recursos naturales en esta región data desde 1746, cuando ya se sacaba la madera de Chimalapas. Expediciones para explorar vías de comunicación y riquezas de la región fueron constantes durante el periodo colonial. A finales del siglo XIX, en la cabecera de 


\section{Iliana Amoroz Solaegui Zoques Chimalapas. Reconfiguraciones...}

Santa María se asientan aserraderos de compañías extranjeras. En el siglo XX, en la década de 1930 llegan compañías madereras nacionales a la zona oriente.

De Teresa (2000) plantea los mecanismos que siguieron los procesos de poblamiento en la región. El primero, de 1800 a 1947, la autora lo caracteriza por un poblamiento espontáneo de los zoques, en la búsqueda de más y mejores tierras de cultivo. El segundo momento, de 1950 a 1995, se entrelazan las estrategias de los zoques y las políticas de colonización impulsadas por el gobierno para trasladar y establecer habitantes de otras regiones. A este segundo periodo corresponde la fundación de las comunidades de la zona oriente.

En 1967 se les otorgan dos Resoluciones Presidenciales por parte del gobierno federal, en las cuales les son reconocidas a los zoques chimalapas 594,000 hectáreas, divididas oficialmente en los municipios de Santa María, 460,000 hectáreas, y San Miguel Chimalapa con 134,000 hectáreas.

Algunas investigaciones han catalogado a los zoques como un grupo étnico en extinción (Barabas y Bartolomé, 1986), pues plantean que muchas de sus tradiciones y costumbres las han perdido, al adoptar prácticas culturales de sus vecinos los zapotecos y de los mestizos con quienes conviven en su territorio. Estos mismos autores también hablan de un proceso de "zapotequización" del Istmo y de los zoques (Barabas y Bartolomé, 1996: 251).

Para nuestro análisis retomamos lo que otros autores han planteado, en relación con la "zapotequización" y las fronteras culturales, Barth (1976: 10) dice que "[...] la interacción de un grupo no conduce a su liquidación como consecuencia del cambio y la aculturación; las diferencias culturales pueden persistir a pesar del contacto interétnico y de la interdependencia”. Por su parte, Díaz Polanco (1981) afirma que la historicidad del fenómeno étnico no puede agotarse en la constatación de que las etnias aparecen y se extinguen, pues de esa manera se deja de lado la importante cuestión de que ellas, mientras existen, también están sometidas a los procesos históricos de los conjunto de la sociedad. 


\section{Iliana AmorozSolaegui Zoques Chimalapas. Reconfiguraciones...}

Otros autores, por su parte, han planteado la conformación de una "etnia chima” (Nigh y Rodríguez, 1995: 170); sin embargo, una etnia en términos etnológicos se define e identifica a partir de la lengua y la historia, Luis Villoro refiere "al conjunto de individuos vinculados por el uso de una lengua o dialecto particular” (Villoro, 1998: 19). En este sentido, el pueblo étnico es el zoque. Sin embargo, tal categoría de etnia la utilizamos no más allá de esta diferenciación. Consideramos que el concepto de etnia ${ }^{7}$ conlleva una fuerte carga colonizadora y racista.

\section{Los otros/nosotros: poblamiento de la zona sur oriente del municipio de San Miguel Chimalapa}

En este apartado presentaremos al segundo actor, esto es la conformación del otro/nosotros chimas, constituido por el nosotros, zoques, y el otros, indígenas tsotsiles y mestizos que llegan a poblar la zona oriente.

Entre 1940 y 1950, con la política de colonización y los proyectos de desarrollo impulsados por el gobierno, llegaron a funcionar en esta zona más de veinte aserraderos, sobre todo de la familia Sánchez Monroy, y de Óscar Moguel y Juan Pérez, grandes terratenientes de Michoacán, Veracruz, Guerrero y Chiapas, que se mantuvieron en la región alrededor de veinte años.

A mediados de 1960, además de los trabajadores mestizos de los aserraderos, en la zona vivían zoques repartidos en los campamentos de Las Delicias, El Coralillo — hoy Ejido Díaz Ordaz-, La Ciénega de León y el Trébol — hoy comunidad Benito Juárez-, la mayoría propiedad de la familia Sánchez Monroy. El aserradero Rosamonsa, mejor conocido como La Ciénega de León, fue uno de los más importantes en la historia de los conflictos. Inició el trámite de titulación en 1949 y culminó en 1952, cuando el gobierno emitió los títulos de propiedad por 1,500 hectáreas (Cruz, 2000).

Los zoques que fueron a poblar estas tierras y a trabajar estos aserraderos procedían de comunidades como Río Blanco, El Palmar

\footnotetext{
${ }^{7}$ El término fue acuñado por los franceses durante su dominio colonial sobre África, para dar cuenta de las especificidades y diferencias culturales entre pueblos. Está originado inequívocamente en la perspectiva cognitiva asociada a la colonialidad del poder (Quijano, 1992).
} 


\section{Iliana Amoroz Solaegui Zoques Chimalapas. Reconfiguraciones...}

y Cuauhtémoc Guadalupe, del centro del municipio de San Miguel Chimalapa. Las causas principales por las que salieron de sus comunidades fueron porque entre las décadas de 1960 y 1970 llegaron al municipio y comunidades aledańas narcotraficantes y partidos políticos, provocando una cadena de violencia y desplazamientos en busca de empleo y de tierra a las ciudades cercanas y a la zona oriente del municipio.

En 1977, algunos trabajadores zoques y mestizos empiezan a organizarse y es así que, por medio de una acción colectiva que llamaron la cadena, expulsan a estas empresas madereras. La estrategia consistió en poner una cadena en el camino que llevaba al aserradero de La Ciénega de León, y otra en el camino al aserradero de Los Pericos, en la clausura de los aserraderos y el decomiso de máquinas, camiones y ganado. A otros mestizos, apoyar el movimiento de resistencia les permitiría tener acceso a la tierra y volverse comuneros.

Se organizaron y pusieron una cadena y con esa cadena ya no hubo paso, se suspendió el saqueo de madera, se decomisó los camiones cargados, toda la maquinaria de la compañía, se detienen todos los animales a cambio de la explotación. A eso se le llamó la cadena, al bloque que duró un año, fue la que dirigieron los señores grandes, mis papás, mis tíos (...) y las mujeres como mi mamá y algunas señoras grandes que estuvieron al frente (entrevista, Benito Juárez, 20/04/02).

Después de este movimiento, que duró más de un año, los aserraderos se declararon en quiebra, suspendieron todas sus actividades en 1977 y salieron de la región.

En 1979 las personas que habían participado en la cadena, zoques y trabajadores, quienes vivían en el campamento El Trébol, fundaron ahí mismo la comunidad Benito Juárez, trasladándose posteriormente a orillas del río Portamonedas. En 1984 se funda la comunidad de San Antonio - antes aserradero El Salto, propiedad de la familia Moguel — también por personas de origen zoque y mestizos que habían participado en la cadena, pero principalmente por tsotsiles y 


\section{Iliana AmorozSolaegui Zoques Chimalapas. Reconfiguraciones...}

tseltales migrantes de Los Altos de Chiapas, apoyados por el gobierno de Chiapas.

Una vez que lograron expulsar a los aserraderos de la región el conflicto por el territorio continuó con los ejidos chiapanecos que aumentaban en la zona, también apoyados por el gobierno de Chiapas. Ya que con el reparto agrario, del que se beneficia la región en la década de 1960, también obtenían títulos de propiedad ejidatarios, por vía de dotación y ampliación en lo que consideraban terrenos nacionales, pese a que históricamente se trataba del territorio comunal de los zoques chimalapas, amparados en sus títulos virreinales y que posteriormente fueron legalmente reconocidos en las resoluciones presidenciales de 1967.

Para cuando son expedidas estas resoluciones ya se encontraban con resolución tres ejidos chiapanecos colindantes con San Miguel: Rodulfo Figueroa - hoy municipio Belisario Domínguez-, Ramón E. Balboa y Nuevo Tenochtitlán. Siendo gobernador del estado de Chiapas el general Absalón Castellanos empieza a apoyar a los propietarios de los aserraderos y a los ejidos chiapanecos dentro de bienes comunales de San Miguel Chimalapa.

Los de Díaz Ordaz defendían su ejido como estado de Chiapas, los chimalapas reclamaban que son bienes comunales y los chiapanecos reclaman que son terrenos nacionales, estos ejidos son más antiguos pero los chimalapas son los dueños verdaderos de las tierras (entrevista, Benito Juárez, 25/08/02).

Fracturas, alianzas, disputas entre las dos partes, comuneros y ejidatarios, provocan en la zona una serie de enfrentamientos entre campesinos, policías y personas de fuera que tenían relación con el gobierno. Debido a los muchos intereses sobre los bosques, tierras y recursos naturales por parte de caciques chiapanecos, los chimas de la comunidad Benito Juárez han sido acusados de delincuentes y narcotraficantes, teniendo en varias ocasiones órdenes de aprensión, lo cual ha afectado la vida cotidiana de los comuneros, sus familias y las comunidades. 


\section{Iliana AmorozSolaegui Zoques Chimalapas. Reconfiguraciones...}

En la década de 1990 la zona sur del municipio de San Miguel se fue poblando de comunidades zoques. La comunidad Sol y Luna en 1991 se funda a dos kilómetros de distancia de las lagunas que llevan el mismo nombre, La Cristalina en 1995; ambas comunidades están constituidas en su mayoría por zoques provenientes de ciudades como Niltepec, Zanatepec, Tapanatepec y La Blanca, población zoque que en la década de 1960 había salido de comunidades del centro del municipio San Miguel Chimalapa.

Estas personas, después de estar algunos años en las ciudades vecinas, decidieron ir a fundar la comunidad Sol y Luna hacia el interior del territorio de los Chimalapas, "nosotros, como somos migueleños, tenemos derecho de trabajar" (entrevista, Sol y Luna, 15/04/04). Antes de levantar sus casas de láminas estuvieron viviendo siete meses en las "cuevas" hechas de piedra amontonada alrededor de las lagunas.

En el año 2000 se ven en la necesidad de reubicarse en la zona que conocían como "La Terminal", cerca de la mojonera de la Piedra de Sol y Luna, que está a dos kilómetros antes de iniciar el camino de ascenso hacia las lagunas. Esta Piedra marca una de las mojoneras del territorio de los Chimalapas, sin embargo, actualmente sólo está la marca en el lugar identificado, pero sin piedra, ya que cuando estas tierras no estaban ocupadas algunas personas del municipio de Zanatepec se la llevaron. ${ }^{8}$ La comunidad se reubica del lado del límite perteneciente a los bienes comunales del municipio San Miguel Chimalapa. La intención era rescatar las tierras en donde estaba explotando la madera el Grupo Ganadero Santa Bárbara.

Esta zona del límite sur del territorio ya tenía propietarios desde antes de que llegaran los zoques migueleños a poblarla. Un supuesto propietario de estas tierras fue Rubén Cacho, quien se dice que vendió las tierras a ochenta personas del Grupo Ganadero Santa Bárbara. Con este propietario no tuvieron problemas, cuentan los comuneros: "sólo metía ganado, el problema fuerte fue cuando los de Santa Bárbara empezaron a sacar madera”.

\footnotetext{
${ }^{8}$ Los comuneros platican que por dos pesos se la puede ver en el museo de la Casa de Cultura del municipio de Zanatepec.
} 


\section{Iliana AmorozSolaegui Zoques Chimalapas. Reconfiguraciones...}

El proceso de fundación de la comunidad de La Cristalina - 5 de noviembre - es parecido al de Sol y Luna. Se funda en 1995 por zoques provenientes principalmente de Zanatepec y Niltepec y originarios del centro del municipio San Miguel. Esta comunidad es la de más difícil acceso. Antes de 2003 sólo se podía llegar a ella caminando o a caballo, mediante un recorrido de aproximadamente cinco horas.

Estas dos comunidades, Sol y Luna y La Cristalina, de relativa nueva creación, están catalogadas de muy alta marginación, lo cual se puede explicar, por una parte, por ser familias desplazadas de su lugar de origen $y$, por otra, debido a su reciente fundación, por lo que carecen de infraestructura y servicios básicos, en contraste con las ventajas que sí encontraron para la caza, la recolección y la pesca. Las dos comunidades actualmente están habitadas por zoques chimalapas y por población mestiza proveniente de otros estados.

En general, las características de identificación social y cultural que comparte la población al interior de las comunidades son: la costumbre, las fiestas patronales, los compromisos matrimoniales, la historia, el tequio, las asambleas generales y extraordinarias, las Comisiones y la defensa del territorio comunal. La lengua es un factor que diferencia a la población zoque, tsotsil y mestiza, así como las diferencias religiosas que llegan a ser muy marcadas en algunas de las comunidades, sin que hasta el momento sean la causa de mayores conflictos.

El territorio es definido por su población como todo aquello que abarca Chimalapas, esto es: las mojoneras, los deslindes, el medio ambiente, la tierra comunal, la selva, la fauna, la flora, los manantiales, el agua, la vivienda, los comuneros y la población en general. La tierra es considerada un aspecto dentro del territorio y es identificada con el trabajo, la vivienda, la parcela y las tierras de cultivo (Talleres. Benito Juárez, Sol y Luna y La Cristalina. 17/04/2002; 24/08/03; 15/08/04).

La organización social y política se da a través de sus Asambleas generales y extraordinarias; se hace tequio y se organizan en comités encargados de alguna obra de construcción específica como la de la iglesia, la escuela o los caminos. Una comisión más que han integrado a su organización es la comisión de defensa del territorio, para la cual designan a algunos comuneros para darle seguimiento a los conflictos agrarios. 


\section{Iliana Amoroz Solaegui Zoques Chimalapas. Reconfiguraciones...}

Ésta es una parte de la historia cultural, social y política de la conformación de la zona oriente y sur del municipio de San Miguel, iniciada por los zoques para obtener reconocimiento de sus bienes comunales, donde ahora conviven indígenas de otras culturas y mestizos que han aceptado vivir bajo el régimen de bienes comunales.

\section{Los otros: políticas de desarrollo, invasiones y saqueo de los recursos}

En este apartado presentamos la conformación del siguiente actor del modelo de las relaciones triádicas, los otros, es decir, el "otro dominante", aquellas personas externas al territorio que invaden, fundan ejidos, saquean los recursos naturales de los Chimalapas, así como las políticas agrarias y el desarrollo promovido por los gobiernos estatal y federal, ajenos a las necesidades de las comunidades. Es decir, la función política — de la seguridad- del territorio de los Chimalapas y los cambios y amenazas que ha sufrido en las últimas décadas, acentuados por políticas capitalistas que tratan de fragmentar el territorio.

\section{Proyectos de desarrollo}

Los proyectos de desarrollo han sido uno de los aspectos fundamentales que ha trastocado la vida de las comunidades chimalapas, además de agravar los conflictos agrarios en la región. Mencionaremos algunos de ellos.

A partir de la década de 1980 se plantearon para la región Chimalapas la construcción de una presa en el río del Corte, conocido como Chicapa-Chimalapa; y un proyecto carretero entre Palomares y Cintalapa que uniría Sayula (Veracruz) con Cintalapa (Chiapas), atravesando las selvas del Uxpanapa, Chimalapas y la Reserva del Ocote. Los chimas han logrado detener estos proyectos y que la carretera se desviara, pues consideran que el impacto que tendría en el medio ambiente, la economía y la cultura de las comunidades sería negativo, además de que nunca fueron consultados respecto de estos planes.

En 2001 se presenta el capítulo Plan Puebla Panamá (PPP), promovido por el presidente Vicente Fox, abarcando nueve estados 


\section{Iliana AmorozSolaegui Zoques Chimalapas. Reconfiguraciones...}

del sureste de México y siete países de Centroamérica (PPP, 2001).? Actualmente este conjunto de proyectos contemplados inicialmente en el PPP es denominado Plan Mesoamericano.

Desde el discurso oficial, las comunidades chimas fueron acusadas de acelerar el deterioro ecológico de la región debido a sus prácticas tradicionales de producción y aprovechamiento de los recursos naturales. Es así como surge para la región la propuesta de declarar una Reserva de la Biosfera (RB) desde 1987, retomándola en 1998, para la cual se considera abarcar 400,000 hectáreas de selva en buen estado de conservación que se encuentran en el centro del territorio.

Aunque en la ley está presente escuchar la opinión de los pueblos indígenas, así como promover la participación y vigilancia de la población en la administración de dichas áreas, no ha sucedido tal cosa, a cambio han intentado ofrecer dinero a los comuneros para que acepten la $\mathrm{RB}$, razón por la cual esta propuesta fue rechazada definitivamente por las comunidades en el año 2003 ante el delegado estatal de la Semarnat: "nuestras tierras y nuestra identidad no están en venta” (Ojarasca, 18/03/02).

En cuanto a la propiedad, la tenencia de la tierra y la situación del agro en México, un cambio sustancial que se desprende de estas políticas de corte neoliberal fue la reforma al artículo 27 constitucional, la cual implicó la finalización del reparto agrario, la parcelación de ejidos y bienes comunales y la certificación individual de la tenencia social de la tierra. Modificado el estatuto jurídico de las superficies ejidales y comunales y enmarcado por la Ley Agraria, se implementa el Programa de Certificación de Derechos Ejidales y Titulación de Solares (Procede). ${ }^{10}$

\footnotetext{
9 Estados: Campeche, Tabasco, Guerrero, Veracruz, Oaxaca, Chiapas, Quintana Roo, Yucatán y Puebla. Países: Belice, Honduras, Nicaragua, Panamá, Costa Rica, El Salvador, Guatemala y México.

${ }^{10}$ Procede se llamó hasta 2013, hoy es el Fondo de Apoyo para Núcleos Agrarios sin Regularizar (FANAR).
} 


\section{Iliana Amoroz Solaegui Zoques Chimalapas. Reconfiguraciones...}

Las condiciones mínimas que la Procuraduría Agraria establece a los ejidos o comunidades para implementar el programa son: 1 . que se encuentren regularizados en términos jurídicos; 2 . que no presenten conflictos internos o de límites con otros; 3 . que no presenten dificultades técnicas para su medición.

De este modo, en la región de los Chimalapas jurídicamente no podría llevarse a cabo el Procede, pues no se cumplen las condiciones, sin embargo, en febrero de 2004 fue anunciada por el presidente Fox ${ }^{11}$ la implementación de estos programas para la región, como la opción para la seguridad de la tierra, dando por concluidos conflictos como el de Santa María con la Colonia Agrícola y Ganadera Cuauhtémoc e ignorando varios, como el de la zona oriente y los ejidos chiapanecos, sin ser atendidos otros problemas - como el saqueo de madera e invasiones- y demandas de las comunidades chimas, como el deslinde de sus tierras, reconocimiento de sus mojoneras y la resolución del conflicto agrario.

A estos programas de derechos ejidales se les suman actualmente los proyectos de explotación minera que están previstos en el municipio de San Miguel Chimalapa, Santo Domingo Zanatepec y San Pedro Tapanatepec, y concesiones principalmente para la explotación de oro, plata, cobre, zinc y plomo con una vigencia de hasta 50 años (Sistema de Administración Minera, Siam, 2014).

\section{Ejidos chiapanecos y políticas agrarias}

Los municipios de Santa María y San Miguel Chimalapa tienen un total de 37 comunidades y un ejido. Sus conflictos agrarios son: hacia el oriente con los ejidos del estado de Chiapas; hacia el sur con los municipios oaxaqueños de Zanatepec, Niltepec, Tapanatepec y Santo Domingo Ingenio; hacia el norte con los poblados del Uxpanapa.

Uno de los problemas más conocidos en la década de 1990 fue el de la Colonia Ganadera San Isidro la Gringa, un paraje que había sido invadido desde 1970, ubicado en el extremo noroeste del territorio, en el municipio de Santa María. Se constituye como Colonia

\footnotetext{
${ }^{11}$ Evento de entrega de tierras al municipio de Santa María Chimalapas, febrero de 2004.
} 


\section{Iliana Amoroz Solaegui Zoques Chimalapas. Reconfiguraciones...}

aprovechando la indefinición de límites comunales y el conflicto con el estado de Chiapas, amparándose en un decreto presidencial de 31 de julio de 1987, posterior a la fecha de las resoluciones presidenciales, que declara como terrenos nacionales una superficie de 40,945 hectáreas (De Teresa, 2000). En 1994 fue devuelto a los comuneros de Santa María vía indemnización por catorce millones de pesos, los cuales se pagaron a 147 ganaderos.

Otro conflicto parecido se dio y se agravó entre 2003 y 2004 en el extremo occidente del mismo municipio, el de la Colonia Agrícola y Ganadera Cuauhtémoc, situación que se fue dando desde la década de 1950, cuando por resolución presidencial se reconocen 40,000 hectáreas a esta Colonia. Sin embargo, poco a poco, durante las décadas que siguieron, los ganaderos se fueron apropiando de 12,850 hectáreas de tierra del municipio de Santa María. Para reclamar la propiedad sobre estas hectáreas, los indígenas zoques inician un juicio agrario en 1996 en demanda de la nulidad del acta de deslinde y plano de la Colonia Cuauhtémoc.

Finalmente en 2004 se logra la devolución de las hectáreas invadidas al municipio de Santa María vía indemnización por 126 millones de pesos a los ganaderos de la Colonia Cuauhtémoc y se soluciona un conflicto que llevaba 47 ańos, considerado "foco rojo" por la Secretaría de la Reforma Agraria (SRA) y que desde principios del ańo 2003 se había agravado con enfrentamientos, desplazados, y el saldo de un muerto.

Los problemas más alarmantes hasta el día de hoy en el territorio de los Chimalapas son con ejidos chiapanecos asentados en los límites con el estado de Chiapas. Los bienes comunales de Chimalapas enfrentan conflictos con 29 de ellos: siete en los límites de San Miguel y 22 en Santa María. En San Miguel tres ejidos cuentan con resolución presidencial anterior a la resolución de los chimas: Ramón E. Balboa, Rodulfo Figueroa y Nuevo Tenochtitlán; dos con resoluciones posteriores: Flor de Chiapas y Gustavo Díaz Ordaz; y dos con acción agraria en trámite en el Tribunal Superior Agrario: Nuevo Tenochtitlán (Ampliación) y Fénix Monte Sinaí. 


\section{Iliana AmorozSolaegui Zoques Chimalapas. Reconfiguraciones...}

Los 22 ejidos asentados en Santa María enfrentan controversia por la tenencia de la tierra y abarcan una superficie aproximada de 50,000 hectáreas del territorio del municipio de Santa María, mientras que los ejidos asentados del lado del municipio de San Miguel abarcan 16,000 hectáreas. En total suman 66,000 hectáreas en disputa agraria que representa $30 \%$ de las 594,000 hectáreas que comprenden en total los bienes comunales del territorio de los Chimalapas.

El gobierno de Chiapas permanentemente reclama 160,000 hectáreas en favor del estado, incluyendo los ejidos. Toda la zona en conflicto se encuentra incluida en lo que Chiapas denomina "Zona noroeste de Cintalapa”, adjudicándose de paso las 300,000 hectáreas conservadas de selva:

Entre 1992 y 1994, en los informes elaborados por la Comisión de Límites del Estado de Chiapas se declara que existe una "selva Chimalapas-Cintalapa" que cuenta con alrededor de 300 mil hectáreas en condiciones "totalmente inalteradas" (...) dentro de una superficie total de 594 mil hectáreas. Esta amplia superficie comprende los municipios de Cintalapa y Ocozocuautla en Chiapas, con una superficie de 178 mil hectáreas (30\%) y el resto de la superficie $(70 \%)$ a los municipios de San Miguel y Santa María Chimalapas (Cruz, 2010).

Se está cuantificando y caracterizando doblemente las tierras comunales del territorio Chimalapa por parte del estado de Chiapas. En 1995, el gobernador de entonces, Patrocinio González Garrido, unilateralmente modifica el artículo $3^{\circ}$ de la Constitución estatal donde se especificaba todo lo relativo a los límites con el estado de Oaxaca, y es decretado por el Congreso local y publicado por el Instituto Nacional de Estadística y Geografía (Inegi) (Noticias, 18/08/03).

Con esta situación, las invasiones y asentamientos ilegales en los bienes comunales de los Chimalapas continúan durante toda la década de 2000. En 2001 llegan diez familias a fundar la comunidad La Orquídea. ${ }^{12}$ Son chiapanecos y su objetivo es instalarse en las tierras

\footnotetext{
${ }^{12}$ Paraje donde antes existía un aserradero, cerca de la comunidad Benito Juárez.
} 


\section{Iliana AmorozSolaegui Zoques Chimalapas. Reconfiguraciones...}

como ejido, sin reconocer los bienes comunales de San Miguel, a lo cual los chimas se oponen rotundamente y han insistido en su desalojo.

En 2003 se dan más invasiones de ganaderos y talamontes chiapanecos en el paraje La Hondonada y por la parte de La Ciénega, ${ }^{13}$ en los límites del conflicto, donde se dan constantes enfrentamientos. Por otra parte, el gobierno del estado de Chiapas constantemente ha expedido permisos forestales a personas de Cintalapa y la población de los ejidos en bienes comunales para explotar bosques y recursos naturales dentro de los bienes comunales del municipio de San Miguel.

Hacia el sur del municipio de San Miguel los conflictos que afectan a las comunidades, principalmente a Sol y Luna y La Cristalina, son invasiones que se intensificaron a partir de 2004 y actualmente siguen en negociación. En este límite del territorio cada vez son más personas que reclaman ser dueñas de tierras de los Chimalapas: por un lado, el municipio de Zanatepec, por otro, el Grupo Ganadero Santa Bárbara del mismo municipio y, por otro más, los ejidos de Pascual Fuentes -El Jícaro_, y el Ejido Plan de Ayala, de Tapanatepec, este último posee titulación por medio del Programa de Certificación de Derechos Ejidales y Titulación de Solares (Procede) en los bienes comunales de los Chimalapas, pero con fecha posterior a las resoluciones presidenciales.

En 2004 ganaderos del Grupo Santa Bárbara, apoyados por el presidente del municipio de Zanatepec, reclamaban el predio El Horizonte de 240 hectáreas, que decían tener los chimas en posesión, recurriendo incluso a acciones de presión para que les sean devueltas. ${ }^{14}$ Las comunidades chimas, para hacer frente a esta ofensiva, fundan otra comunidad en los límites de este predio en disputa: La Esperanza, para tratar de detener la invasión; sin embargo, por divisiones y falta de apoyo del municipio de San Miguel terminó siendo desalojada por las mismas autoridades municipales.

Es hasta 2011 que los chimas y los bienes comunales del territorio zoque chimalapa viven la intensidad de las invasiones chiapanecas.

\footnotetext{
${ }^{13}$ Aserradero donde inició el movimiento de la cadena. Actualmente está abandonado por encontrarse en los límites del conflicto.

${ }^{14}$ Los pequeños propietarios y ganaderos bloquearon el 11 de marzo de 2004 la carretera Panamericana a la altura de Zanatepec, reclamando se les devolvieran las tierras que estaban invadiendo comuneros chimas.
} 


\section{Iliana AmorozSolaegui Zoques Chimalapas. Reconfiguraciones...}

Este año, el entonces gobernador de Chiapas, Juan Sabines, envía una iniciativa al Congreso estatal para declarar la creación de un nuevo municipio en la región, misma que fue aprobada por el Decreto número 008 expedido por el Congreso del estado de Chiapas en el que se crea el denominado municipio "Belisario Domínguez" —antes ejido Rodulfo Figueroa-, en jurisdicción territorial del pueblo zoque chimalapa, invadiendo sus bienes comunales y los límites del estado de Oaxaca.

Lo que vuelve a dejar claro que en Chimalapas el conflicto fundamental es de carácter agrario, que implica la falta de deslinde de las 594,000 hectáreas del territorio zoque chimalapa reconocidas en las resoluciones presidenciales de los dos municipios así como el reconocimiento de la propiedad comunal del territorio zoque chimalapa. Mientras que el estado de Chiapas insiste en un problema de límites interestatales, reclamando como suyas poco más de 160,000 hectáreas de tierras que pertenecen a los Chimalapas, encontrándose estatalmente dentro de Oaxaca.

Hasta entonces los chimas no habían tenido respuesta alguna a sus demandas de atención al conflicto agrario por parte del gobierno del estado de Oaxaca. En esta ocasión contaron con el apoyo del Poder Ejecutivo del Oaxaca. Crearon la "Estrategia Integral Conjunta para la Defensa del Territorio y los Bienes Naturales Comunes de los Chimalapas", quienes interpusieron controversias constitucionales ante el mencionado decreto.

Sin embargo, la crisis social, el rezago y la marginación de los habitantes de la zona oriente — sin energía eléctrica, servicios de salud, ni educativos_- así como su demanda agraria principal, siguen siendo relegadas o condicionadas. Al día de hoy, el gobierno de Oaxaca se manifiesta públicamente a favor de la defensa de los Chimalapas, incluso promoviendo una inversión social millonaria para fortalecer el desarrollo social y productivo de la región. ${ }^{15}$

La realidad en las comunidades chimas de la zona oriente de San Miguel es una fuerte presión y condicionamiento por parte del

15 "Retira Cué su compromiso en defensa de los Chimalapas", 9 de junio, 2014. Disponible en: http://www.tiempoenlinea.com.mx/index.php/oaxaca/10708-reiteracue-su-compromiso-en-defensa-de-los-chimalapas. 


\section{Iliana AmorozSolaegui Zoques Chimalapas. Reconfiguraciones...}

gobierno de Oaxaca para que acepten al nuevo municipio chiapaneco en sus bienes comunales, les han condicionado servicios de energía eléctrica, educación, salud, necesidades que desde hace mucho debieron atenderse. Por otro lado, el gobierno les ha prohibido a los comuneros la libre expresión para difundir la información de lo que está pasando al interior de la región (entrevista comuneros, Oaxaca, 17/07/14).

Estas dinámicas institucionales, ajenas a las realidades de las comunidades y con total indiferencia, alevosía y ventaja, ocasionan que se incrementen la tensión y confrontación entre ejidatarios y comuneros y en la vida cotidiana de las comunidades en su lucha por sobrevivir.

\section{Nosotros/nosotros: la defensa del territorio}

En este apartado presentamos al cuarto actor de las relaciones triádicas: el nosotros/nosotros, constituido por el nosotros los zoques, y por los otros/ nosotros, las personas que no son zoques pero que viven en el territorio y lo defienden; quienes en conjunto se identifican como chimas. En las relaciones entre estos dos actores incide el tercer actor antagonista, el otro dominante, los actores externos que amenazan y agreden el territorio.

Es así como el nosotros/nosotros constituye un proceso de identidad colectiva con un referente territorial, que incluye procesos de etnicidad y constitución política de los chimas, lo que les permite un posicionamiento identitario y político frente a los otros.

Sin duda, el hecho histórico que marca la defensa de esta parte del territorio chimalapa y de las comunidades que a partir de entonces se establecen es la expulsión del aserradero de la familia Sánchez Monroy en la década de 1970, cuando realizan la acción colectiva de la cadena. Esta acción se logró en alianza con los trabajadores zoques y mestizos de los aserraderos.

Los proyectos de desarrollo que han podido detener los zoques chimas en la década de 1990 fueron el proyecto de presas ChicapaChimalapa; el desvío de la carretera de cuatro carriles; los proyectos forestales financiados por el Banco Interamericano de Desarrollo (BID) y el Banco Mundial; además de que detuvieron la iniciativa 


\section{Iliana AmorozSolaegui Zoques Chimalapas. Reconfiguraciones...}

e imposición en reiteradas ocasiones de una Reserva de la Biosfera, que desde 1987 se ha planeado para ocupar 400,000 hectáreas de los Chimalapas (Informe a OIT, 2001). Han impedido, al mismo tiempo, que la región sea militarizada, pues con el pretexto del "conflicto entre los límites de estados" se insiste desde el gobierno federal en la presencia del ejército.

Entre las estrategias para defender su territorio, los chimas de las comunidades de Benito Juárez, Sol y Luna y La Cristalina en 2001 propusieron un Plan Integral de Desarrollo, donde plantean la creación de un Área Comunal de Manejo, Conservación y Aprovechamiento de los Recursos Naturales como alternativa a la Reserva de la Biosfera, e incluso a la Reserva Ecológica Campesina (REC), esta última en conjunto con la organización Maderas del Pueblo desde hace ya bastante tiempo, donde proponen que las comunidades puedan manejar, administrar los recursos naturales, sin instituciones, y con ONG intermediarias.

Hasta ahora no se ha logrado declarar la Reserva de la Biosfera propuesta por el gobierno, pero tampoco ha habido interés de las instituciones en la Reserva Ecológica Campesina, mucho menos en el Plan Integral de Desarrollo que los chimas elaboraron, donde demuestran que la población puede cuidar de la biodiversidad y de su territorio.

Las comunidades chimas, en la cuestión agraria, han insistido y demandado a las autoridades agrarias el deslinde de sus tierras por 594,000 hectáreas, mismas que reconocen las resoluciones presidenciales de 1967 y que sería la solución, para los chimas, a las invasiones y deterioro de la región. Ante la indiferencia de las instituciones, han intentado hacerlo por su cuenta en reiteradas ocasiones.

Un intento se dio durante 2003 y 2004, cuando el conflicto con los ganaderos de Zanatepec en la zona sur se agudizó. A través de una comisión de negociación entre instituciones, comuneros e invasores, se acuerda iniciar el brecheo del lado sur del territorio, de las mojoneras La Jineta a La Caseta. Sin embargo, ahora el problema ya no era solamente conseguir iniciar el brecheo, sino decidir con base en qué Plano se haría. A finales de la década de 1990 les fue presentada, a 


\section{Iliana AmorozSolaegui Zoques Chimalapas. Reconfiguraciones...}

los comuneros chimas, la Carpeta Básica de Derechos Agrarios a cargo de la entonces Procuraduría Agraria (PA), donde, para sorpresa de las comunidades chimalapas, en el Plano Definitivo, que marca los límites del territorio, no se reconocen las 594,000 hectáreas ni las mojoneras que ellos defienden, a lo que los chimas respondieron con la propuesta del Plano Proyecto, elaborado de acuerdo con las resoluciones presidenciales de 1967. La Jineta es una de las mojoneras que delimita el territorio hacia el sur, punto para llegar en línea recta a la mojonera El Ocotillo, al otro extremo sur.

En un recorrido se encontraron tres mojoneras de La Jineta, ubicadas en lugares distintos, con fechas diferentes, la tercera que identificaron los chimas como la suya estaba destruida. Este descubrimiento favorecía a los ejidos — que tenían incluso títulos de propiedad expedidos por el Procede - y a las invasiones de ganaderos.

Con este movimiento de mojoneras, son aproximadamente trece mil hectáreas de los bienes comunales las que se encuentran en conflicto con ejidatarios y ganaderos del municipio de Zanatepec y demás municipios vecinos hacia el sur (ver Mapa 2). Ante la negativa de las instituciones y los supuestos propietarios, los chimas deciden contratar a un ingeniero por su cuenta - aunque sin validez oficialpara marcar los puntos colindantes entre las mojoneras que delimitan el territorio hacia el sur. El estudio se basó en la resolución presidencial de 1967, en Acta de Deslinde de 1991 y el Plano Proyecto de 1996.

En dicho estudio se identificaron las mojoneras que los chimas reconocen, y concluye:

Al trasladarse a la mojonera de La Jineta, a La Jineta 2 y a la del Ocotillo 1 y 2 , se forma un área que abarca aproximadamente 2,580 hectáreas, dejando al poblado de Sol y Luna fuera de los terrenos comunales de San Miguel Chimalapa. Se da constancia de la falta de validación social y técnica de los vértices y linderos en esta zona, las razones históricas y los motivos e intereses que lo generaron no pueden ser explicados con estos métodos. Pero es evidente que ha existido en este tramo (El Ocotillo- La Jineta) un replanteamiento en la ubicación de mojoneras o de los vértices a finales de 1980 y 


\section{Iliana AmorozSolaegui Zoques Chimalapas. Reconfiguraciones...}

principios de 1990 que no fueron en su oportunidad socialmente consensuados. ${ }^{16}$

Queda en evidencia la ineficacia de las instituciones agrarias, la discrecionalidad con la que han actuado y la gran responsabilidad que tienen en muchos de los conflictos agrarios al sobreponer títulos de propiedad. También se demuestra la corrupción con la que han actuado algunas autoridades de Bienes Comunales del municipio de San Miguel Chimalapa.

Mapa 2.

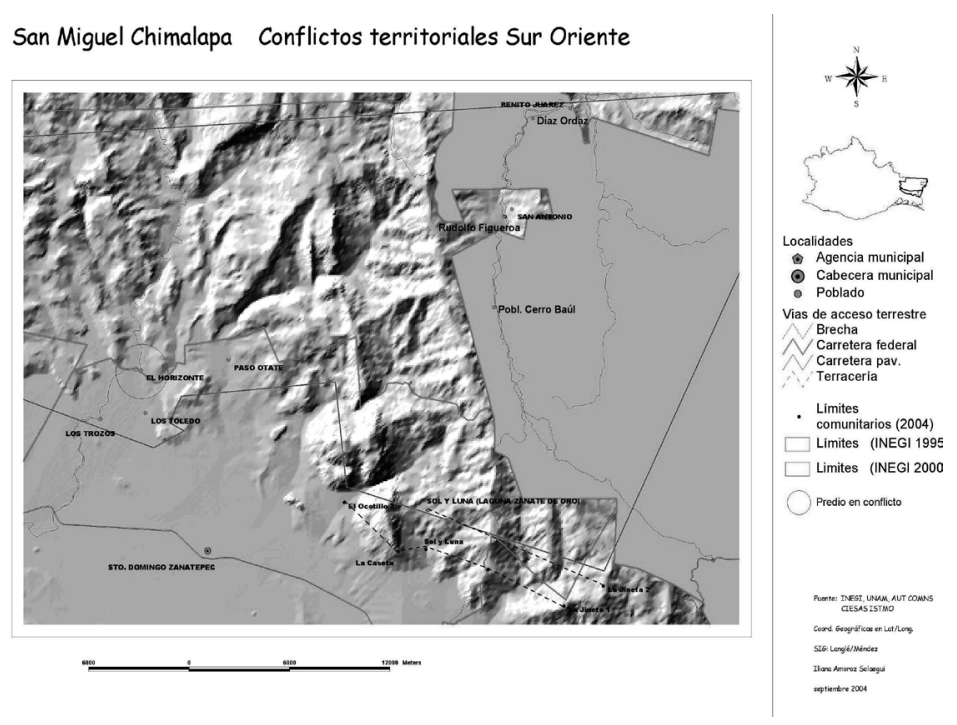

A esta situación se suman los grandes intereses que ejidatarios, caciques, ganaderos, talamontes y narcotraficantes tienen sobre el territorio, esto los aleja totalmente del reconocimiento histórico, social, cultural, económico y político que representa el territorio para los zoques chimalapas quienes lo habitan desde hace siglos.

${ }^{16}$ Estudio Técnico para el reconocimiento de la ubicación de puntos Ocotillo-La Jineta, Servicios Forestales y Ambientales. Responsable técnico, ingeniero José Luis Naranjo Arias. Responsable operativo, biólogo Víctor Manuel Tena Carranza. Asistente técnico, T.F. Gerobuam Hernández Jiménez. Marzo, 2004. 


\section{Iliana Amoroz Solaegui Zoques Chimalapas. Reconfiguraciones...}

\section{Conclusión}

En la historia de conflictos en el territorio de los Chimalapas, cada actor tiene la propia, parafraseando a Ana María Alonso: historias contrarias populares que surgen en el espacio creado por la disyunción entre las representaciones oficiales y los significados incrustados en la experiencia de vida de las personas (Alonso, 1988); cada grupo tiene su propia versión de los hechos, cada uno dice tener la razón; se contraponen, se enfrentan, negocian; el gobierno aparece como mediador y reconciliador, en el peor de los casos como represor, pero no reconoce la gran responsabilidad que tiene en estos conflictos al sobreponer planos de uno y otro lado, donde las mojoneras y las fronteras se mueven de acuerdo con los intereses de un grupo de poder, afectando principalmente a los y las indígenas y campesinos que habitan la región y paralizando la resolución del conflicto agrario.

Pese a la presión que actualmente está viviendo la población de las comunidades de la zona oriente del municipio San Miguel Chimalapa, para que acepten al recién creado municipio chiapaneco Belisario Domínguez, el actuar de los gobiernos estatales de Chiapas y Oaxaca ha sido presionar a los comuneros, dividirlos, condicionarles los programas sociales y servicios básicos. Las comunidades chimas siguen demandando el respeto a sus bienes comunales, porque esas tierras y ese territorio pertenecen por derecho ancestral a los zoques.

Grandes intereses parecen estar en juego en la región de los Chimalapas, intereses políticos y económicos puestos en sus bosques cada vez más deforestados, en sus montañas de grandes alturas hoy aprovechadas por los narcotraficantes, en sus recursos naturales, la fauna y la flora que corren el riesgo de extinguirse. La gente sigue estando en segundo plano, acusada y amedrentada por cortar un árbol, por vender palma camedor, por portar armas para la cacería, por hablar, acusados de narcotraficantes o de "peleoneros" por defenderse.

En este proceso de expansión capitalista, saqueo y despojo, el proceso de defensa del territorio para los chimas sigue siendo una prioridad irrenunciable e irremplazable, como lo demuestra su organización en las últimas décadas. La defensa del territorio por parte de las y los chimas adquiere dimensiones globales, al llevar implícita la defensa de 


\section{Iliana Amoroz Solaegui Zoques Chimalapas. Reconfiguraciones...}

lo colectivo y la defensa de la vida. A contracorriente, las comunidades chimas tendrán que seguir resistiendo, constituyendo su autonomía, defendiendo su territorio como territorio zoque chimalapa, como bien común y colectivo.

\section{Bibliografía citada}

Almeyra, Guillermo y Rebeca Alfonso, 2004, El Plan Puebla Panamá en el Istmo de Tehuantepec, Universidad de la Ciudad de México, México.

Alonso, Ana María, 1988, "Los efectos de verdad: representaciones del pasado y el imaginario de comunidad", en Journal of Historical Sociology, vol. I, núm. 1, marzo, pp. 35-57.

Báez-Jorge, Félix, 1973, Los zoques popolucas, INI, Conaculta, México. Barabas, Alicia y Miguel Bartolomé, 1986, "Rebeliones e insurrecciones indígenas en Oaxaca", en Alicia Barabas y Miguel Alberto Bartolomé, Etnicidad y pluralismo cultural: la dinámica étnica en Oaxaca, Conaculta, México.

Barth, Fredrik, 1976, Los grupos étnicos y sus fronteras, FCE, México.

Bartolomé, Miguel y Alicia Barabas, 1993, Historia zoque, INAH (Serie de historias étnicas núm. 7), Oaxaca.

Bartolomé, Miguel y Alicia Barabas, 1996, La pluralidad en peligro: procesos de transfiguración y extinción cultural en Oaxaca, INAH, INI, México.

Bonfil Batalla, Guillermo, 1994, México Profundo. Una civilización negada, Grijalbo, México.

Bonnemaison, Jöel, 1981, "Voyage autour du territoire", en L'Espace Géographique, núm. 4, pp. 249-262, Doin, 8, place de l'Odéom, París-VI.

Clark, John y Michael Blake, 1993, “Los Mokaya”, en Esponda, Víctor (compilador), La población indigena de Chiapas, Gobierno del Estado de Chiapas.

Coronado Malagón, Marcela, 2004, Procesos de etnicidad de los zapotecos del Istmo de Tehuantepec: una relación triádica entre la resistencia y la dominación, Tesis de Doctorado en Antropología de la 


\section{Iliana Amoroz Solaegui Zoques Chimalapas. Reconfiguraciones...}

Escuela Nacional de Antropología e Historia, ENAH, México. Cruz Coutiño, Arturo, 2000, "Historia del aserradero más grande de Chiapas", en Revista del Sur, Chiapas.

Cruz Monje, Rosalinda, 2010, "El proceso de frontera-frente en la zona de El Chayotal de las montañas del noroeste de Cintalapa, Chiapas, 1950-2004', en Nahmad, Salomón, Margarita Dalton y Abraham Nahón (coordinadores), Aproximaciones a la región del Istmo. Diversidad multiétnica y socioeconómica en una región estratégica para el país, CIESAS, Culturas Populares, Conaculta, Secretaría de Culturas y Artes, Gobierno del Estado de Oaxaca, Oaxaca.

De Teresa, Ana Paula y Gilberto Hernández, 2000, Los vaivenes de la selva. El proceso de reconstitución del territorio zoque de los Chimalapas, UAMI, Semarnap, Conacyt, México.

Díaz Polanco, Héctor, 1981, "Etnia, clase y cuestión nacional”, en Cuadernos Políticos, núm. 30, octubre-diciembre, pp. 53-65, Editorial ERA, México, D.F.

García, Miguel Ángel, 1999, "La historia Chimalapa: una paciente y tenaz lucha indígena por un rico territorio en disputa", en Revista Chiapas, núm. 8, IIE UNAM, ERA, México.

García, Miguel Ángel, Ana Silvia Ortiz y Rosendo Montiel, 2000, Chimalapas: nuestra experiencia en ordenamiento ecológico participativo, Department for International DevelopmentMaderas del Pueblo del Sureste, A. C., México.

Hoffmann, Odile, 2001, "Del territorio étnico a laciudad: las expresiones de identidad negra en Colombia a principios del siglo XIX", en Grupo de Investigación Territorialidades, Territorio y Cultura, Territorios en conflicto y cambio sociocultural, Universidad de Caldas, Colombia.

Lee, Thomas A., Jr., 1983, "Frans Blom y la antropología contemporánea de los mixe-zoques y los mayas", en Lorenzo Ochoa y Thomas Lee (editores), Antropología e historia de los mixe-zoques y mayas, Universidad Nacional Autónoma, Brigham Young University, México.

Lowe, Gareth W, 1983, "Los olmecas, mayas y mixe-zoques", en 


\section{Iliana AmorozSolaegui Zoques Chimalapas. Reconfiguraciones...}

Lorenzo Ochoa y Thomas Lee (editores), Antropología e historia de los mixe-zoques y mayas, Universidad Nacional Autónoma de México, Brigham Young University, México.

Plan Puebla Panamá, 2001, Manual de Organización de la Coordinación General, Secretaría de Relaciones Exteriores, Secretaría para América Latina y El Caribe, Disponible en http://www.sre.gob. $\mathrm{mx} /$ images/stories/docnormateca/manadmin/2012/mocgppp.pdf Nigh, Ronald y Nemesio Rodríguez, 1995, Territorios violados: indios, medio ambiente y desarrollo en América Latina, INI, Conaculta, México.

OIT, 1987, Convenio 169 Sobre Pueblos Indigenas y Tribales en Paises Independientes, Organización Internacional del Trabajo, OIT. PNUMA, 2000, Corredor Biológico Mesoamericano, en http://rolac. unep.mx/

PPP, 2001, "Propuesta de proyectos para la región", Plan Puebla Panamá, Secretaría de Medio Ambiente y Recursos Naturales, México.

VECH, 1990, Tequio por los Chimalapas, Vocalía Ejecutiva para los Chimalapas, Gobierno de Oaxaca, México.

Velasco Toro, José, 1975, "Perspectiva histórica", en Villa Rojas (coordinador), Los zoques de Chiapas, INI, SEP, México.

Quijano, Aníbal, 1992, "Raza, etnia y nación en Mariátegui: cuestiones abiertas", en JCM y Europa: la otra cara del descubrimiento, Amauta, Lima, Perú.

Villoro, Luis, 1998, Estado plural, pluralidad de culturas, Paidós, UNAM, Biblioteca Iberoamericana de Ensayo núm. 3, México. Wichmann, Søren, 1995, The relationship among the mixe-zoquean languages of México, University of Utah Press, Salt Lake City, US.

Hemerografía

Gómez, Emanuel, "Los Chimalapas, el futuro de la selva zoque", Suplemento Ojarasca-La Jornada, 18 de marzo de 2002, México. 
Iliana Amoroz Solaegui Zoques Chimalapas. Reconfiguraciones...

"Se queda Chiapas con 28 ejidos de Oaxaca, Oaxaca", Noticias, 18 de agosto de 2003, Oaxaca.

"Retira Cué su compromiso en defensa de los Chimalapas", Tiempo en Línea, 9 de junio de 2014, Disponible en http://www. tiempoenlinea.com.mx/index.php/oaxaca/10708-reitera-cuesu-compromiso-en-defensa-de-los-chimalapas

Secretaría de la Reforma Agraria, SRA, “Comunicado de prensa 080”, 22 de agosto de 2003.

Documentos de archivo

Estudio Técnico para el reconocimiento de la ubicación de puntos Ocotillo-La Jineta, Servicios Forestales y Ambientales. Responsable técnico, ingeniero José Luis Naranjo Arias. Responsable operativo, biólogo Víctor Manuel Tena Carranza. Asistente técnico, T.F. Gerobuam Hernández Jiménez, marzo, 2004.

Sitio web

Informe de los chimas a la Organización Internacional del Trabajo, OIT, 2001, disponible en http://www.geocities.com/chimalapasmx/ oit/contraiforme.htm

Sistema de Administración Minera, SIAM, disponible en http://www. siam.economia.gob.mx/ (fecha de consulta: 23 de octubre de 2014). 